\title{
DEVELOPMENT OF SIMULATION MODEL FOR Dry Clutch Engagement ANALYSIS
}

\author{
Mirsad Trobradovic, Almir Blazevic, Boran Pikula \& Dzevad Bibic
}
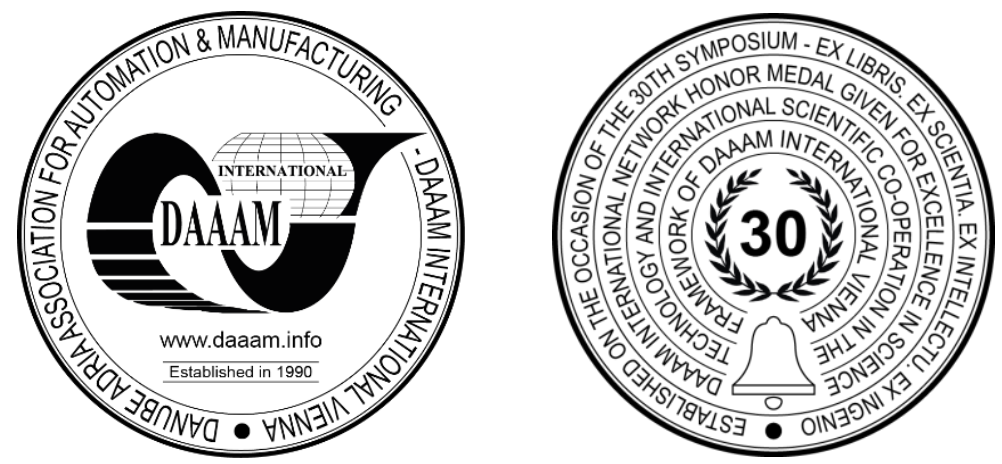

This Publication has to be referred as: Trobradovic, M[irsad]; Blazevic, A[lmir]; Pikula, B[oran] \& Bibic, D[zevad] (2020). Development of Simulation Model for Dry Clutch Engagement Analysis, Proceedings of the 31st DAAAM International Symposium, pp.0819-0825, B. Katalinic (Ed.), Published by DAAAM International, ISBN 978-3-90273429-7, ISSN 1726-9679, Vienna, Austria

DOI: $10.2507 / 31$ st.daaam.proceedings. 114

\begin{abstract}
The clutch is a very important part of vehicle's transmission, whether it is a manual, automated or dual-clutch transmission. Its task is to transmit engine torque to the gearbox and enable the vehicle to move-off from a stationary position comfortably. It also plays a role in the process of gear change. Single plate dry clutch engagement process has been analysed in this paper. Also, the basic influencing parameters on the clutch engagement process have been defined. Mathematical model has been developed to simulate the operation of the clutch, with emphasise on pressure plate dynamics. Using the MATLAB/Simulink software package, computer program has been developed to simulate clutch engagement process. Verification has been done by using literature available experimental data.
\end{abstract}

Keywords: vehicle transmission; dry clutch engagement; clutch torque; simulation model; MATLAB/Simulink.

\section{Introduction}

The clutch performs a multiple role in vehicle transmission system, whether it is manual, automated or dual-clutch transmission. It should transmit engine torque to the gearbox for all operating conditions as well as dampen engine torsional vibrations. The clutch allows the gear to be changed during gear shifting process, and allows a vehicle moving-off from standstill in controlled manner. In that sense, ensuring precise and reliable clutch operation (clutch engagement and disengagement) is very important for the overall efficiency and comfort of modern vehicle gearboxes. Due to its simplicity and long service life dry friction clutches are used for manual and most of dual-clutch transmissions of modern vehicle [1]. Single plate dry clutch is analysed in this paper.

In the process of dry friction clutch engagement, the engine torque is transmitted by the friction mechanism from the clutch pressure plate to the clutch drive plate and further to the gearbox input shaft. For the vehicle moving-off from standstill the clutch should allow smooth engagement and gradual transmission of torque from the engine to the vehicle wheels. This is achieved by engaging the clutch in such a way that the clutch friction torque gradually increases from zero to the maximum value. The key influence on the clutch friction torque during clutch engagement has normal force which acts on the friction surfaces [2], [3]. This force is due to normal force acting on the pressure plate as well as axial elasticity of the clutch plate [3]. 
In the clutch engaged state, the force acting on the pressure plate (clamping force) is result of the action of the clutch diaphragm spring. Engagement and disengagement of the clutch is performed by changing the magnitude of normal force acting on the pressure plate. It is done by the action of release force on the clutch release bearing which is located at the end of diaphragm spring fingers. These forces are usually expressed as a function of the pressure plate travel or clutch release travel. Proper modulation of these forces is crucial for smooth clutch engagement. Therefore, the proper modulation of these forces is crucial for automatic control of the clutch engagement process in automated transmissions (automated manual and dual-clutch transmissions) [4], [5].

In order to establish relationship between clutch torque and pressure plate travel, analysis of the clutch engagement process was carried out. A simplified mathematical model that can describe the dynamics of the clutch pressure plate has been developed. Developed model is solved using MATLAB / Simulink software package.

\section{Clutch torque and pressure plate dynamic}

To model dry friction clutch engagement process it is necessary to determine the clutch friction torque. The clutch friction torque depends on the friction coefficient and contact pressure on the clutch friction surfaces. In the general case it is given by the expression [6]:

$$
T_{C}=\int_{r_{C}}^{R_{C}} \int_{0}^{2 \pi} \mu_{C} p \rho_{C}^{2} d \rho d \alpha=2 \pi \int_{r_{C}}^{R_{C}} \mu_{C} p \rho_{C}^{2} d \rho
$$

where $\mu_{C}$ is friction coefficient, $p$ contact pressure on the clutch friction surfaces, $\rho_{C}$ radii of the friction surface, $\rho$, $\alpha$ radial and angular geometric variables of the friction surfaces, $R_{C}, r_{C}$ outer and inner radii of the clutch friction surface.

For uniform contact pressure distribution ( $p=$ const.), normal force acting on the contact surfaces [7] is given as:

$$
F_{N, C}=p \pi\left(R_{C}^{2}-r_{C}^{2}\right)
$$

and friction torque as:

$$
T_{C}=\mu_{C} F_{N, C} \frac{2}{3}\left(\frac{R_{C}^{3}}{R_{C}^{2}}-\frac{r_{C}^{3}}{r_{C}^{2}}\right)
$$

Taking into account the number of friction surfaces, the expression for the clutch friction torque is:

$$
T_{C}=\mu_{C} F_{P P} Z \frac{2}{3}\left(\frac{R_{C}^{3}}{R_{C}^{2}}-\frac{r_{C}^{3}}{r_{C}^{2}}\right)
$$

where $F_{P P}$ is clamping force of pressure plate, $z$ number of friction surfaces.

The clamping force $F_{P P}$ with which the pressure plate acts on the friction surfaces is the result of the action of the diaphragm spring on the pressure plate. When mounting the coupling, the diaphragm spring is compressed, and the resulting pre-load force of the spring is transmitted to the pressure plate. This value of the diaphragm spring force, for fully engaged clutch, also represents the maximum value of the clamping force. The maximum force value is maintained at all times while the clutch is fully engaged. The diaphragm spring belongs to the group of disc springs of special design [8]. The standard model used to define the characteristics of the disc spring is the so-called Almen \& Laszlo formula [9].

During clutch engagement, release force acts on the diaphragm spring fingers. As the diaphragm spring rests on one side on the pressure plate and on the other on the clutch housing its fingers act as a lever. Due to the action of the release force there is a decrease in the clamping force. If the diaphragm spring fingers are considered rigid (no deformation occurs under the action of the release force), the relationship between the release force and the clamping force of the pressure plate is given by the expression:

$$
F_{P P}=F_{D S}-F_{B} \frac{b}{a}
$$

where $F_{D S}$ is pre-load force of the diaphragm spring (maximum value of the clamping force), $F_{B}$ release force (clutch actuation force), $a$ distance between the diaphragm spring supports on the housing and the pressure plate, $b$ distance between the diaphragm spring supports on the housing and the places of action of the release force. The value of $\frac{b}{a}=$ $i_{D S}$ is called the diaphragm spring lever ratio. 
For the assumption of the rigidity of the diaphragm spring fingers (spring lever), the relation between the pressure plate travel $\left(x_{P P}\right)$ and the release travel $\left(x_{B}\right)$ is given by the expression:

$$
x_{B}=i_{D S} x_{P P}
$$

Due to the elastic deformations of different elements of the clutch plate assembly under the action of the release force, there is a delay in the travel of the pressure plate in relation to the release travel [10]. Also, the axial elasticity of the clutch plate significantly affects the travel of the pressure plate. The relation between the pressure plate travel and release travel in real operating conditions is nonlinear ( $\left.i_{D S} \neq c o n s t\right)$, and is determined by experiments [11].

The axial elasticity of the clutch plate has the task of ensuring a gradual increase in pressure on the contact friction surfaces and thus reducing the impact loads during clutch engagement. The axial elasticity of the clutch plate has a key influence on gradual increase of clutch torque during clutch engagement [3]. The axial elasticity of the clutch plate has a nonlinear character and is determined experimentally [10], [12] or using FEM analysis [12].

Return flat springs (strap plates) connect the clutch housing to the pressure plate and transfer torque from the clutch housing to the pressure plate. In addition, these springs allow the pressure plate to move axially when the clutch is disengaged [1]. The stiffness of these springs can be determined by the expression:

$$
k_{S}=\frac{n_{S} h_{S}^{3} b_{S} E}{l_{S}^{3}}
$$

where $n_{S}$ is number of springs, $h_{S}$ spring thickness, $b_{S}$ spring width, $l_{S}$ spring length, $E$ Young's modulus of elasticity. Once the characteristics of the clutch assembly elements have been defined, a mathematical model to determine the parameters of the pressure plate movement during clutch engagement process can be set up (Figure 1). Using this model, clamping force, as a function of pressure plate travel or release travel, can be determined, for any given value of release force.
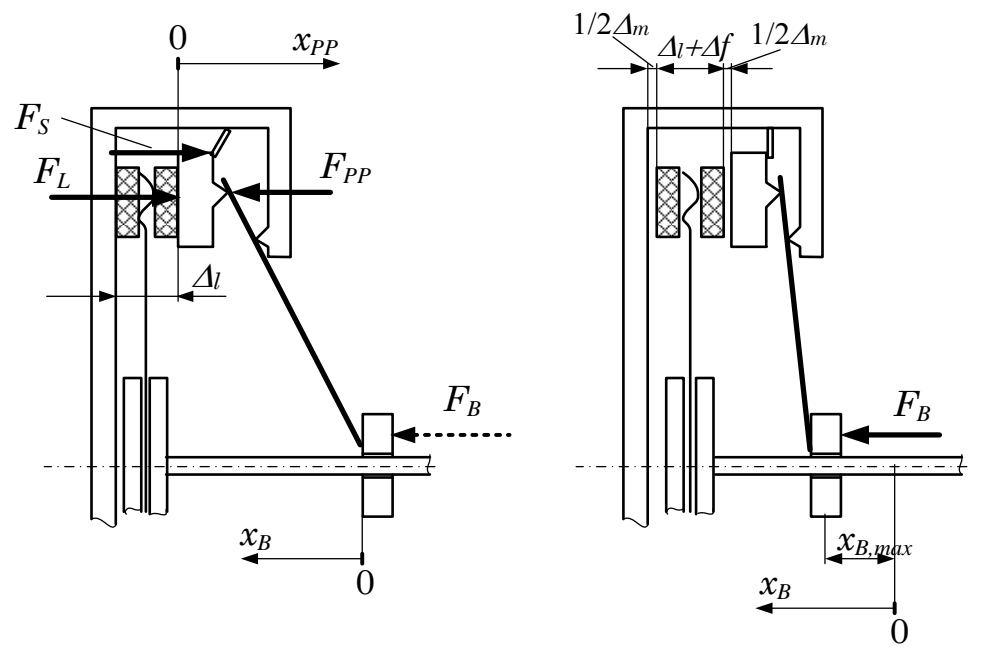

Fig. 1. Forces acting on clutch elements and axial displacements during clutch engagement process Clutch engaged (left), Clutch disengaged (right)

Return flat springs force is defined by the expression:

$$
F_{S}=k_{S}\left(x_{P P, \max }-x_{P P}\right)
$$

where $k_{S}$ is return flat springs stiffness, $x_{P P}$ pressure plate travel, $x_{P P, \max }$ maximal pressure plate travel for disengaged clutch. Maximal pressure plate travel for disengaged clutch is given by expression:

$$
x_{P P, \max }=\Delta_{m}+\Delta_{f}
$$

where $\Delta_{f}$ is maximum elastic travel of the clutch plate, $\Delta_{m}$ gap between the pressure plate and the clutch plate for the disengaged clutch. The axial elastic force of the clutch plate (cushion spring force) is determined by the expression:

$$
F_{L}=\left\{\begin{array}{cc}
F_{L}\left(x_{P P}\right), & 0<x_{P P} \leq \Delta_{f} \\
0, & x_{P P}>\Delta_{f}
\end{array}\right.
$$


and its maximal value is:

$$
F_{L, \max }=F_{D S}
$$

Now, the pressure plate dynamic during clutch engagement can be described by the equation:

$$
F_{S}+F_{L}-m_{P P} \ddot{x}_{P P}-b_{P P} \dot{x}_{P P}-F_{P P}=0
$$

or in another form as:

$$
m_{P P} \ddot{x}_{P P}+b_{P P} \dot{x}_{P P}-k_{S}\left(x_{P P, \max }-x_{P P}\right)-F_{L}\left(x_{P P}\right)-\left(F_{D S}-F_{B} i_{D S}\right)=0
$$

where $m_{P P}$ is pressure plate mass, $b_{P P}$ damping coefficient.

\section{MATLAB/Simulink model for pressure plate dynamic simulation}

The MATLAB/Simulink software package was used to solve the equations of pressure plate dynamics. Simulink is a software package intended for simulation of dynamic systems and is very often used in the analysis of vehicle dynamics as well as in the simulation of dynamic systems of motor vehicles [13], [14]. Simulink offers a library of solvers, each of which represents a specific method for solving ordinary differential equations. An implicit method with a variable step was chosen to solve the developed model (ode23tb). It is an implicit Runge-Kutta formula that uses a combination of a trapezoidal rule and a second-order backward differentiation formula. By using this method, stability, accuracy and satisfactory calculation time were achieved. MATLAB/Simulink model for pressure plate dynamic simulation is shown in Figure 2.

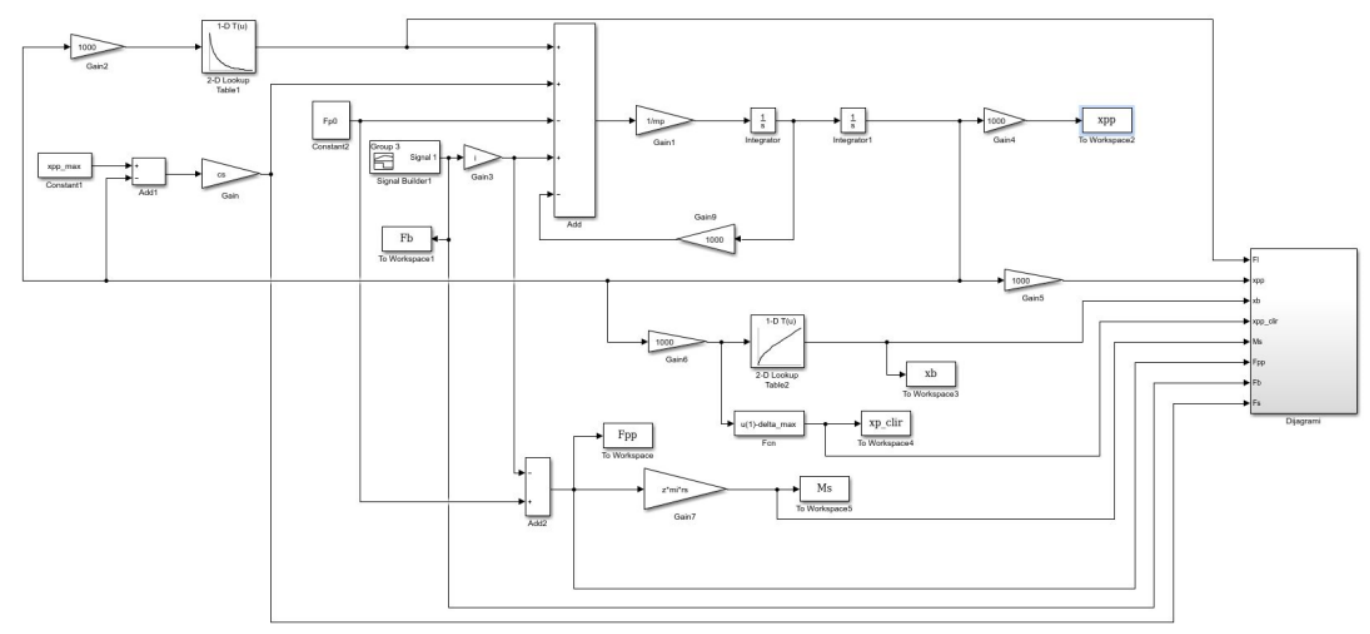

Fig. 2. MATLAB/Simulink model for pressure plate dynamic simulation

\section{Model verification and clutch dynamic analysis}

Using a developed computer program, a simulation of the clutch engagement process was performed. The simulation was performed for one single plate dry clutch of a middle class passenger car. The main clutch parameters required for the calculation are given in Table 1.

\begin{tabular}{|c|c||c|c|}
\hline Parameter & Value & Parameter & Value \\
\hline$F_{D S}$ & $4880 \mathrm{~N}$ & $R_{C}$ & $115 \mathrm{~mm}$ \\
\hline$k_{S}$ & $43453 \mathrm{~N} / \mathrm{m}$ & $r_{C}$ & $85 \mathrm{~mm}$ \\
\hline$I_{D S}$ & 4 & $x_{P P, \max }$ & $3 \mathrm{~mm}$ \\
\hline$m_{P P}$ & $1 \mathrm{~kg}$ & $\Delta_{m}$ & $1 \mathrm{~mm}$ \\
\hline$\mu_{C}$ & 0,3 & & \\
\hline
\end{tabular}

Table 1. Clutch model parameters

Experimental value of clutch plate axial spring characteristic (cushion spring force) and relationship between pressure plate travel and release travel (diaphragm spring lever ratio) [10] are given in Figure 3. 


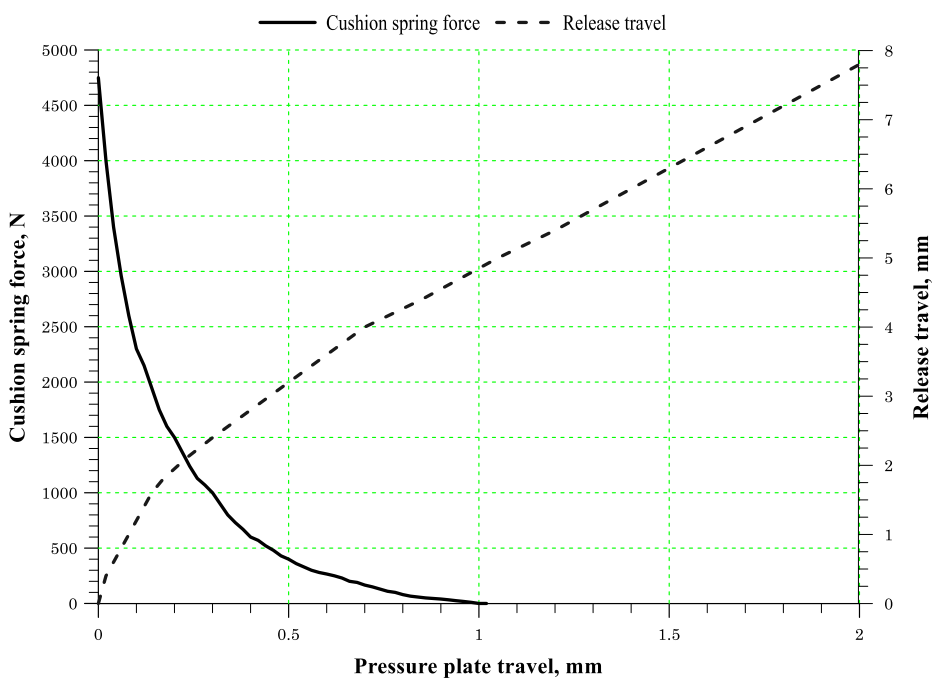

Fig. 3. Clutch plate axial spring characteristic and diaphragm spring lever ratio - experimental data [10]

Verification of developed model has been done by using literature available experimental data [10] (Figure 4 and Figure 5).

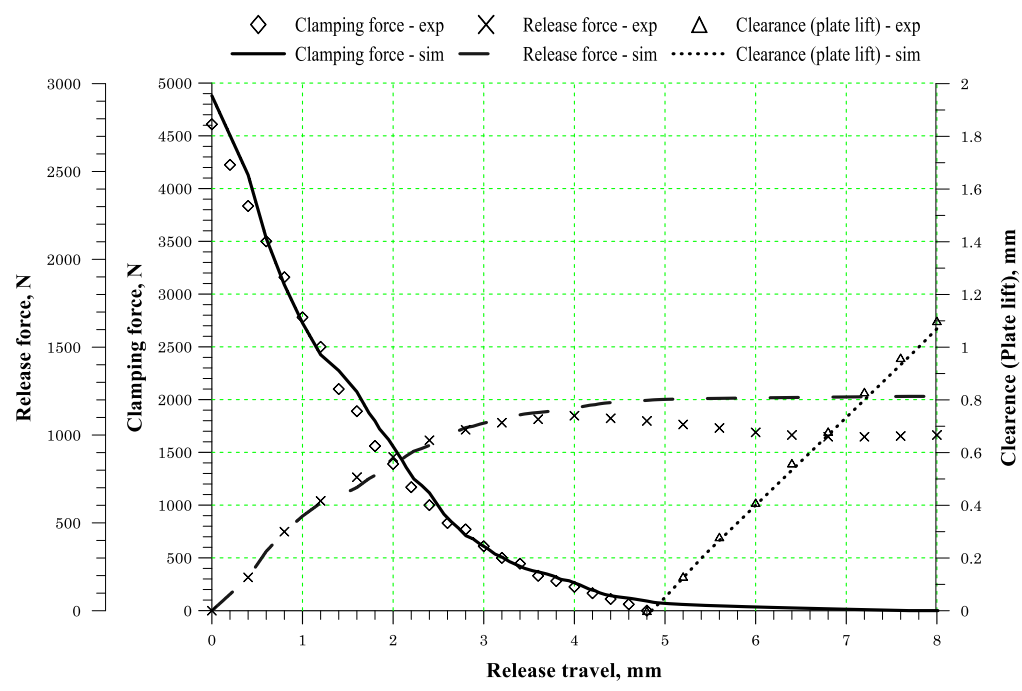

Fig. 4. - Clutch force characteristics during clutch engagement - simulation vs. experimental [10] data

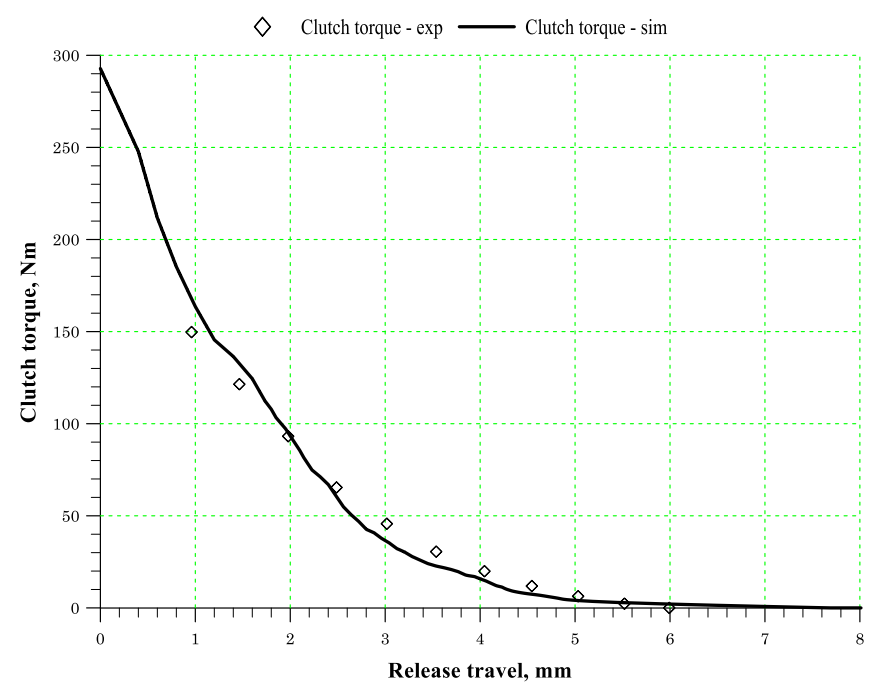

Fig. 5. - Clutch torque characteristic during clutch engagement - simulation vs. experimental [10] data 
The results obtained by the simulation show good correlation with the experimental data. The calculated result also corresponds well with the results of the other studies [2], [3]. There is difference between experimental and simulation data of release force value for release travel above $5 \mathrm{~mm}$. But, considering this is the area where the clutch is fully disengaged it does not affect the results of further analysis.

After the developed model is fully verified, clamping force and clutch torque can be calculated. Figure 6 shows the calculated values of clamping force and clutch torque as function of the pressure plate travel, for a given value of the release force (actuation force). It can be noticed that the clutch plate axial elasticity has a key influence on the characteristic of the clutch torque. By selecting the appropriate axial stiffness of the clutch plate, it is possible to achieve the desired gradual increase of clutch torque during clutch engagement.

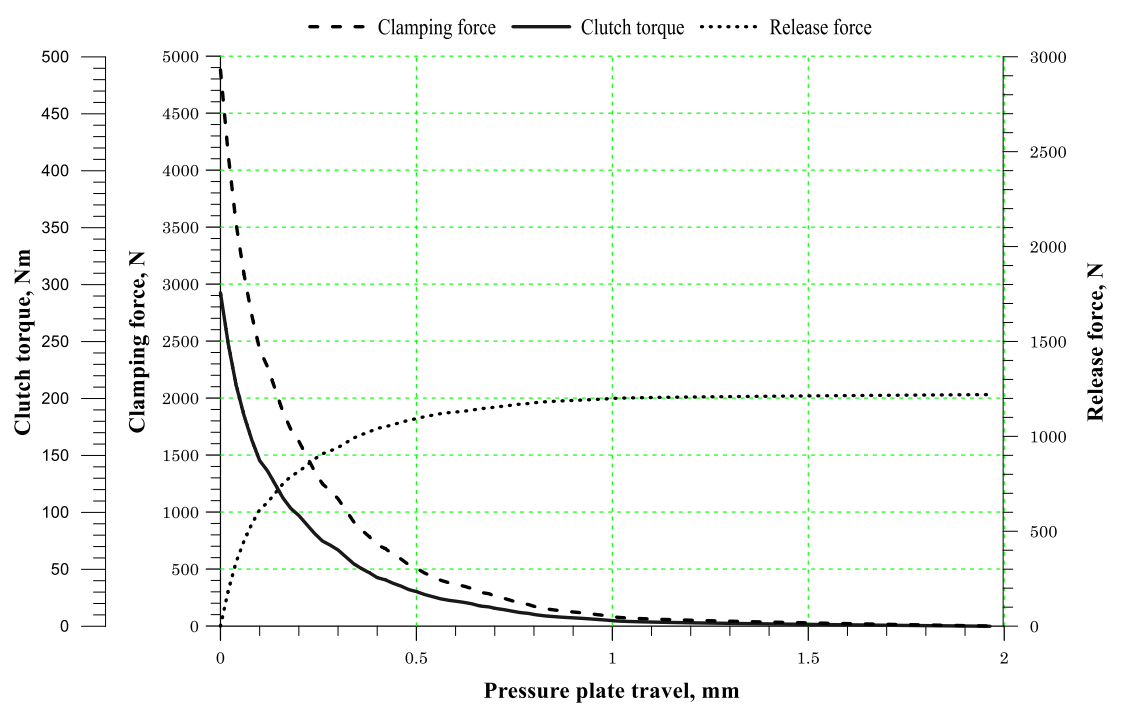

Fig. 6. - Clutch torque characteristic during clutch engagement as a function of pressure plate travel

\section{Conclusion}

Single plate dry clutch engagement process has been analysed in this paper. The basic influencing parameters on the clutch engagement process have been defined. Mathematical model has been developed to simulate the operation of the clutch, with emphasis on pressure plate dynamic. Using the MATLAB/Simulink software package, computer program has been developed to simulate clutch engagement process. Verification has been done by using literature available experimental data. The results obtained by the simulation show good correlation with the experimental data. Based on obtained results it can be noticed that the clutch plate axial elasticity has key influence on the characteristic of the clutch torque. By selecting the appropriate axial stiffness of the clutch plate, it is possible to achieve the desired gradual increase of clutch torque during clutch engagement.

The change of clutch characteristics is very important in the mechatronic control of the clutch operation of modern automated transmissions. In further research emphasis will be placed on investigation of the clutch characteristics in real exploitation condition (influence of vehicle mileage). The research will be based on a combination of experimental measurements and the use of advanced computer methods.

\section{References}

[1] Naunheimer, H.; Bertsche, B.; Ryborz, J. \& Novak, W. (2011). Automotive Transmissions: Fundamentals, Selection, Design and Application, Second Edition, Springer-Verlag Berlin Heidelberg, ISBN 978-3-642-16213-8, Heidelberg

[2] Vasca, F.; Iannelli, L.; Senatore, A. \& Scafati, M. T. (2008). Modelling Torque Transmissibility for Automotive Dry Clutch Engagement, Proceedings of 2008 American Control Conference, 2008, Seattle, USA, ISBN: 978-14244-2079-7, pp. 306-311, IEEE, New York, DOI: 10.1109/ACC.2008.4586508

[3] Pisaturo, M. (2014). Dry clutch for automated manual transmissions, Structural analysis and control strategies, Ph.D. Dissertation, University of Salerno, Italy, http://elea.unisa.it:8080/xmlui/handle/10556/1765

[4] Dolcini, P. J.; Canudas de Wit, C. \& Béchart, H. (2010). Dry Clutch Control for Automotive Applications, Springer-Verlag London Limited, ISBN 978-1-84996-067-0, London

[5] Lucente, G.; Montanari. M. \& Rossi, C. (2007). Modelling of an Automated Manual Transmission System, Mechatronics, Vol.17, No. 2-3, 2007, pp. 73-91, DOI: 10.1016/j.mechatronics.2006.11.002

[6] Milidrag, S. (1983), Motor Vehicle Design, Part one - Power transmission and torque transformation systems of modern motor vehicles, University of Sarajevo, Faculty of Mechanical Engineering, Sarajevo 
[7] Khurmi, R. S. \& Gupta, J. K. (2005), Theory of Machines, 14th Edition, S. Chand \& Company Ltd, ISBN 9788121925242, New Delhi, India

[8] https://schnorr.com/wp-content/uploads/2018/05/Schnorr-Engineering-Design-Handbook.pdf, (2003). Schnorr GmbH, Handbook for Disc Springs, Accessed on: 2020-09-15

[9] Almen, J. O. \& Laszlo, A. (1936). The Uniform-Section Disk Spring, Transaction of the ASME, Research Paper RP-58-10, pp. 305-314

[10] Maucher P. (1986), Optimized Clutch Design Release Load and Operating Comfort, Third LUK Clutch Symposium, April 1986, LuK GmbH \& Co. KG, Available from:

https://www.schaeffler.com/remotemedien/media/_shared_media/08_media_library/01_publications/schaeffler_2/symp osia_1/downloads_11/04_Optimized_Clutch_Design_-_Release_Load_and_Operating_Comfort_1.pdf, Accessed on 2016-04-05

[11] Schaffler Automotive Aftermarket. (2015). LuK Clutch Course: Introduction to clutch technology for cars and LCV's, Schaffler Automotive Aftermarket GmbH \& Co KG, 2015

[12] Cappetti, N.; Pisaturo, M. \& Senatore, A. (2012). Modelling the cushion spring characteristic to enhance the automated dry-clutch performance: The temperature effect, Proc. I MechE, Part D: J. Automobile Engineering, Volume 226, No. 11, 2012, pp. 1472-1482, DOI: 10.1177/0954407012445967

[13] Likaj, R.; Bruqi, M.; Shala, A. \& Bajrami, X. (2016). Optimal Design and Analysis of Quarter Vehicle Suspension System by Using Matlab, Proceedings of the 27th DAAAM International Symposium, pp.0082-0090, B. Katalinic (Ed.), Published by DAAAM International, ISBN 978-3-902734-08-2, ISSN 1726-9679, Vienna, Austria, DOI: 10.2507/27th.daaam.proceedings.012

[14] Beles, H.; Rus, A.; Dragomir, G.; Mitran, T.; Trusca, D.\& Tolea, B. (2016). Researches Regarding the Continuous Improvement of the ABS (Anti-Lock Braking System) Operation for the Passenger Cars, Proceedings of the 26th DAAAM International Symposium, pp.0196-0205, B. Katalinic (Ed.), Published by DAAAM International, ISBN 978-3-902734-07-5, ISSN 1726-9679, Vienna, Austria, DOI:10.2507/26th.daaam.proceedings.027 